\title{
Promoting smoke-free environments in Latin America: a comparison of methods to assess secondhand smoke exposure
}

\author{
Erika Avila-Tang, PhD, MHS, (1-2) Mark J Travers, PhD, MS, ${ }^{(3)}$ Ana Navas-Acien, MD, PhD. ${ }^{(1-2,4)}$
}

\author{
Avila-Tang E,Travers MJ, Navas-Acien A. \\ Promoting smoke-free environments \\ in Latin America: a comparison of methods \\ to assess secondhand smoke exposure. \\ Salud Publica Mex 2010;52 suppl 2:SI38-SI 48.
}

\begin{abstract}
Secondhand smoke (SHS) contains toxicants and carcinogens that are known to cause premature death and disease. Objectively measuring SHS exposure can support and evaluate smoke-free legislations. In Latin America, the most commonly used methods to measure SHS exposure are airborne nicotine and respirable suspended particles $\left(\mathrm{PM}_{2.5}\right)$. Here we present results from studies conducted in public places and homes across Latin American countries.Airborne nicotine was detected in most locations between 2002-2006, before the implementation of $100 \%$ smoke-free legislation in Uruguay, Panama, Guatemala and other large cities within Latin America. Between 2006 and 2008, PM 2.5 levels were found to be five times higher in places where smoking was present at the time of sampling compared to those without smoking. Measuring SHS exposure across Latin America has increased our understanding of the magnitude of exposure in this region and results have been used to effectively promote smoke-free legislation.
\end{abstract}

Keywords: air pollution, tobacco smoke; nicotine; particulate matter; surveillance

\author{
Avila-Tang E,Travers MJ, Navas-Acien A. \\ Promoción de ambientes libres de humo \\ en América Latina: una comparación de métodos \\ para evaluar la exposición a humo de tabaco. \\ Salud Publica Mex 2010;52 supl 2:SI38-SI48.
}

\section{Resumen}

El humo de tabaco $(\mathrm{HT})$ contiene tóxicos y carcinógenos que causan muerte prematura y enfermedades. La medición objetiva de la exposición en el ambiente a HT puede apoyar y evaluar las legislaciones que prohiben fumar.Aquí presentamos resultados de estudios realizados en lugares públicos y hogares latinoamericanos usando los métodos más comunes para esta exposición: nicotina y partículas respirables $\left(\mathrm{PM}_{2.5}\right)$. Se detectó nicotina en el aire de la mayoría de los lugares muestreados entre 2002-2006, antes de la ejecución de la legislación $100 \%$ libre de humo en Uruguay, Panamá, y Guatemala. Entre 2006-2008, los niveles de PM $_{2.5}$ resultaron ser cinco veces mayores en lugares donde personas fumaban comparado con lugares sin fumadores. Medir la exposición al HT en América Latina ha aumentado nuestra comprensión de la magnitud de la exposición en esta región y ha servido para promover eficazmente legislación libre de humo de tabaco.

Keywords: contaminación por humo de tabaco; nicotina; material particulado; vigilancia

(I) Institute for Global Tobacco Control, Johns Hopkins Bloomberg School of Public Health. Baltimore, Maryland, USA.

(2) Department of Epidemiology, Johns Hopkins Bloomberg School of Public Health. Baltimore, Maryland, USA.

(3) Department of Health Behavior, Roswell Park Cancer Institute. Buffalo, New York, USA.

(4) Department of Environmental Health Sciences, Johns Hopkins Bloomberg School of Public Health. Maryland, USA.

Received on: March 22,2010 - Accepted on: April 21, 2010

Address reprint requests to: Erika Avila- Tang, PhD, MHS. Department of Epidemiology, Johns Hopkins Bloomberg School of Public Health 627 N.Washington St. 2nd floor. Baltimore, Maryland, USA 2I 205

E-mail: etang@jhsph.edu 
Cecondhand smoke (SHS), a mixture of mainstream and sidestream tobacco smoke, contains well known toxicants and carcinogens that cause premature death and disease worldwide. ${ }^{1}$ Mainstream smoke is the tobacco smoke exhaled by the smoker whereas sidestream smoke is the tobacco smoke released from the burning cigarette. ${ }^{1}$ In 2001, the Pan American Health Organization (PAHO) launched the Smoke-Free Americas initiative to mobilize action in support of smoke-free communities, workplaces and homes. The World Health Organization Framework Convention on Tobacco Control (WHO-FCTC), the United Nations first public health treaty, entered into force in February 2005. The FCTC was developed in response to the globalization of the tobacco epidemic and has been adopted by 168 countries (parties) as of March $4^{\text {th }}$, 2010, including 26 countries from the Americas. Article 8 of the WHO-FCTC and its implementation guidelines legally binds all parties to adopt and implement comprehensive smoke-free legislations in all public places and workplaces to protect all people from exposure to tobacco smoke. ${ }^{2,3}$

The WHO-FCTC indicates that smoke-free legislation should be monitored and evaluated, and objective measurement of SHS exposure can play a key role. First, such measurements quantify the levels of SHS to which people are exposed in critical locations. Second, determining SHS exposure can be used to assess health risks associated with SHS. Third, SHS levels can be used to educate policy makers and the population at large about SHS occurrence and the importance of enacting smoke-free legislations to eliminate health risks associated with SHS exposure. Finally, objective measures of SHS are excellent tools to evaluate smoke-free legislation once the law has been implemented.

In this review, we present a summary of the methods used to measure exposure to SHS in Latin America, results obtained using these methods, and potential next steps for the region.

\section{Methods and environments for monitoring exposure to SHS}

In general, a good marker of SHS exposure should be easily and accurately measured at an affordable cost, providing a valid assessment of SHS exposure as a whole. ${ }^{4}$ However, SHS is a dynamic and complex mixture of thousands of compounds in vapor and particulate phases. This has important implications for measuring SHS in the air, as it is not possible to directly measure SHS in its entirety. To facilitate the understanding of total suspended particles (TSP) dynamic behavior, Daisey ${ }^{5}$ proposed grouping TSP compounds into 5 major components according to their physicochemical properties (physical state, vapor pressure, and type of compound): 1) very volatile organic compounds (VVOCs) such as formaldehyde, 2) volatile organic compounds (VOCs) such as benzene, 3) semivolatile organic compounds (SVOCs) such as nicotine, 4) particulate matter (PM) and its organic compounds such as benzo[a]pyrene, and 5) gas-phase inorganic compounds such as carbon monoxide.

Each of these different components will behave differently in the environment. The primary determinants of PM and VVOC are the amount of smoking and ventilation rates, with $20-30 \%$ of PM also being deposited on surfaces. ${ }^{6,7}$ Deposition is the process by which aerosol particles collect or deposit themselves on solid surfaces, decreasing the concentration of the particles in the air over time. For VOCs and SVOCs, such as nicotine, significant amounts of the compound will also sorb (adhere) onto room surfaces. This sorption will decrease the concentration of the SHS component in the air. Subsequent desorption (i.e. reemission into the environment), however, will increase the concentration of the component in the air. The amount and time-scale across which the sorption and desorption occurs is a function of the specific SHS component in question, ventilation rate, and the amount and type of surfaces (e.g. furnishings) in the room. Exposure to these compounds can hence occur hours, days, or even weeks after active smoking has stopped and these compounds are adsorbed and desorbed into the air of the room. ${ }^{6}$

Dozens of different markers of SHS in the air have been measured, including nicotine, respirable particles, 3-ethenylpyridine (3-EP), polycyclic aromatic hydrocarbons (PAHs), carbon monoxide, and acrolein. Each marker has advantages and disadvantages in terms of specificity, sensitivity, cost and ease of determination. Furthermore, the choice of marker will also depend on the specific question being addressed and the environment studied. Nevertheless, two methods have become the most commonly used for determining SHS exposure in different environments: airborne nicotine and respirable suspended particles. The two methods are compared side-by-side in Table I.

\section{Air nicotine}

Airborne nicotine concentrations are well correlated with the number of cigarettes smoked and with respirable PM generated by the burning cigarette. They also provide reasonable estimates of exposure to the rest of tobacco components. ${ }^{5,7}$ Nicotine is a particularly attractive marker because tobacco smoke is its only source in most environments (i.e., it is specific to tobacco smoke) and the measurement methods, based on a small passive 


\section{Comparison of SHS eXPOSURE ASSESSMENT METHODS}

Airborne nicotine (passive sampling)
Particulate matter ( $\mathrm{PM}_{25}$, active sampling)

\begin{tabular}{|c|c|c|}
\hline Method & $\begin{array}{l}\text { Passive sampling using a small filter badge hung in an area of interest. } \\
\text { The nicotine collected by the filter is later analyzed in a laboratory } \\
\text { for an integrated value of airborne nicotine concentration in the } \\
\text { area of interest over the duration of sampling. }\end{array}$ & $\begin{array}{l}\text { Portable battery operated machine with a vacuum pump } \\
\text { and integrated laser that samples the air continuously and } \\
\text { stores measurements into memory. Data can be down- } \\
\text { loaded and viewed immediately after sampling. }\end{array}$ \\
\hline Time scale & $\begin{array}{l}\text { Duration of sampling depends on the amount of nicotine in the air } \\
\text { but typically requires I-2 days to I-2 weeks of sampling. For instance } \\
\text { in a bar or nightclub where smoking is allowed I day of sampling is } \\
\text { generally sufficient to provide a precise quantification of nicotine } \\
\text { in that environment. For any location, a week of sampling has the } \\
\text { advantage to provide a good estimate of time weighted average } \\
\text { concentrations. }\end{array}$ & $\begin{array}{l}\text { Measurements are taken continuously and stored in me- } \\
\text { mory as often as once per second for } 6 \text { - I } 4 \text { hours depending } \\
\text { on batteries used. Longer sampling would require plugging } \\
\text { in and securing the device. Allows for the examination of } \\
\text { changes in SHS exposure over time. Allows for the mea- } \\
\text { surement of peak concentrations that are not seen with } \\
\text { integrated methods. }\end{array}$ \\
\hline Sensitivity & $\begin{array}{l}\text { A sufficient amount of nicotine must be collected on the filter in } \\
\text { order to perform quantification in the laboratory. Current laboratory } \\
\text { methods are very sensitive allowing for the quantification of } \geq 0.0026 \\
\mu \mathrm{g} / \mathrm{ml} \text { of nicotine. For instance, I hour of sampling is sufficient to } \\
\text { detect an average concentration of } 0.22 \mu \mathrm{g} / \mathrm{m}^{3} \text { in an environment } \\
\text { where this concentration is constant during the hour of sampling. }\end{array}$ & $\begin{array}{l}\text { Highly sensitive to tobacco smoke; the machine detects } \\
\text { levels as low as I microgram per cubic meter of PM while } \\
\text { cigarettes emit large quantities of PM, about I4 } 000 \text { mi- } \\
\text { crograms per cigarette. }\end{array}$ \\
\hline Specificity & $\begin{array}{l}\text { Highly specific to tobacco smoke. Tobacco is generally the only } \\
\text { source of nicotine. }\end{array}$ & $\begin{array}{l}\text { PM is not specific to tobacco smoke and there are many } \\
\text { other sources of PM present at all times. Especially at low } \\
\text { concentrations it may be difficult to distinguish tobacco } \\
\text { smoke PM from other sources. }\end{array}$ \\
\hline $\begin{array}{l}\text { Correlation between } \\
\text { markers }\end{array}$ & \multicolumn{2}{|c|}{$\begin{array}{l}\text { Both are correlated with other SHS constituents. Especially in places where there is consistent smoking there is a good correlation } \\
\text { between nicotine and } \mathrm{PM}_{2.5} \text { with an increase of about } 10 \text { micrograms of } \mathrm{PM}_{2.5} \text { for each I microgram of nicotine. }\end{array}$} \\
\hline Communication & $\begin{array}{l}\text { Because there is no safe level of SHS exposure the concentration } \\
\text { of nicotine in the environment should be zero (i.e. undetectable). } \\
\text { Any level of exposure increases health risk, although the risk is } \\
\text { substantially higher with increasing concentrations. Nicotine itself } \\
\text { can be of health interest as it may have some cardiovascular effects. } \\
\text { Comparisons of air nicotine concentrations in different locations, } \\
\text { including smoke-free environments are powerful tools in support } \\
\text { of smoke-free initiatives. }\end{array}$ & $\begin{array}{l}\text { PM2.5 has known direct health effects in terms of mor- } \\
\text { bidity and mortality. There are existing health standards } \\
\text { for PM2.5 in outdoor air (USEPA and WHO) that can be } \\
\text { used to communicate the relative harm of PM2.5 levels in } \\
\text { places with smoking. The continuous nature of sampling } \\
\text { allows for the creation of real-time plots showing levels } \\
\text { minute-by-minute which can be powerful communication } \\
\text { tools (e.g. Figure 5). }\end{array}$ \\
\hline Cost & $\begin{array}{l}\text { No expensive equipment to buy up front and minimal operating } \\
\text { cost. Per sample laboratory costs including the filter badge are } \\
\sim \$ 40 \text { - } 100 \text { USD. }\end{array}$ & $\begin{array}{l}\text { High initial investment ( } \$ 4000 \text { USD) but minimal ope- } \\
\text { rating cost. No per sample costs, i.e. no laboratory costs } \\
\text { or consumables. }\end{array}$ \\
\hline Training protocols & Readily available (e.g. www.shsmonitoring.org) & Readily available (e.g. www.tobaccofreeair.org) \\
\hline
\end{tabular}

filter-badge, are accurate, precise, relatively inexpensive and easy to use..$^{7-9}$ The quantification of SHS with airborne nicotine is generally made by passive sampling, a method that does not rely on mechanized air pumping. The sampling device is a small, lightweight, circular plastic badge containing a filter treated with sodium bisulfate (Figure 1). As air passes through a porous membrane, nicotine in the air is absorbed into the filter. ${ }^{8}$

After the sampling devices have been in place for a period of time in the location of interest (e.g. one to two weeks), they are sent to a laboratory where the nicotine collected by the filter is extracted into heptane with an internal standard, and then injected into a gas chromatograph, coupled with a nitrogen phosphorus detector and a capillary column. ${ }^{8,10}$ The lowest amount of nicotine that the laboratory method/instrument has been able to determine in a 7-day sample is around 0.001 $\mu \mathrm{g} / \mathrm{m}^{3}$, although the limit of detection can vary across different laboratories. For quality control purposes, it is important to use around 10\% duplicate samples and at least $10 \%$ blanks. Duplicate samples, a second monitor placed next to the main sampler, are used to determine how repeatable the laboratory analysis is. Correlation coefficients between 0.85 and 0.97 have been reported between duplicate and original samples. ${ }^{11-13}$ Blanks are monitors that are opened for $3-5$ seconds at the sampling site, stored, and analyzed with the rest of the monitors. These blank samples are used to assess background 

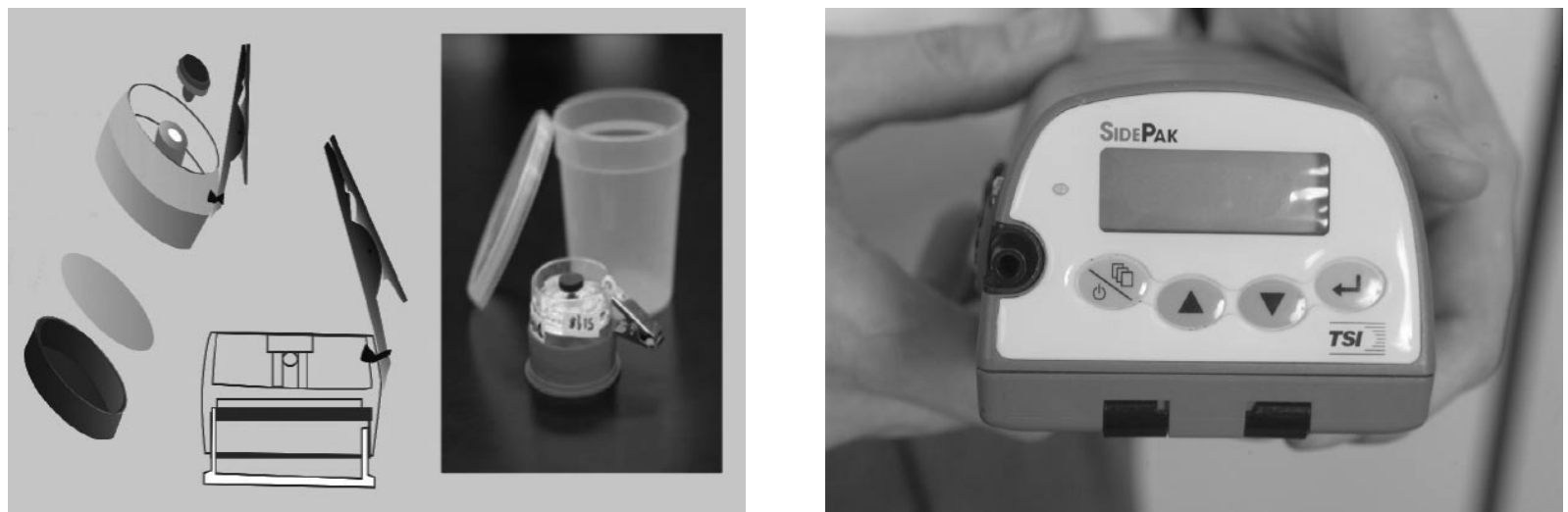

Figure I. Passive monitor (left) used to measure nicotine in the air and SidePak AM5 I 0 Personal Aerosol MoniTOR (RIGHT) (TSI INC., MINNESOTA, USA)

nicotine levels trapped by the filter during shipping, storage and manipulation of the sampling devices. Final concentrations are calculated after subtraction of nicotine background levels from these blank samples. Because nicotine directly relates to tobacco smoke, there is no safe level of air nicotine and nicotine should be undetectable in all indoor environments. Protocols and analysis using this method are readily available at www. shsmonitoring.org.

\section{Particulate matter}

PM can be divided into categories based on size. Respirable suspended particulates (RSP) refer only to particles small enough to be inhaled into the lower airways of the lungs. The maximum particle size for RSP is generally considered 3.5 or 4 microns. $\mathrm{PM}_{2.5}$ is a measure of the mass concentration of particles less than 2.5 microns in diameter. It is commonly used to assess SHS as it closely approximates the respirable fraction (RSP) and there are existing outdoor air quality standards based on $\mathrm{PM}_{2.5}$ concentrations that can be used for comparison. ${ }^{14,15}$ Virtually all PM in tobacco smoke is less than one micron in diameter, with the median particle size around $0.2 \mu \mathrm{m} .{ }^{16,17}$ Other properties of particles, besides mass concentration, can be measured including particle count and surface chemistry, ${ }^{18}$ although the relevance of these measures for secondhand monitoring is less clear.

In contrast to nicotine, PM is not specific to tobacco smoke and thus measurements in environments where smoking occurs must be compared to concentrations in comparable environments where smoking does not occur. In environments without smoking, sources of PM could be related to the presence of burning ovens and candles or to varying levels of outdoor pollution. Like nicotine, measured concentrations of SHS-associated particulate range about 100-fold, from 5 to $500 \mu \mathrm{g} / \mathrm{m}^{3}$, over a wide variety of indoor environments, ${ }^{19}$ although extreme levels of several thousand micrograms per cubic meter are not rare in some indoor environments (e.g. in certain bars and nightclubs). Indoor environments with smoking commonly have concentrations of $\mathrm{PM}_{2.5}$ and/ or RSP in the range of 10-20 or even more times higher than the maximum allowed by the Environmental Protection Agency (EPA) concentrations for outdoor pollution. ${ }^{14,20}$

The novelty in PM monitoring is the availability of portable, user-friendly, affordable instruments capable of real-time continuous monitoring (one measurement every second to minutes). ${ }^{21}$ The continuous nature of measurement allows for examination of changes in tobacco smoke levels over time. These instruments allow multiple assessments of indoor air quality and are suited to check compliance with smoking policy rules. PM measurements can also be compared with health based national air quality standards for outdoor air. ${ }^{14}$ Moreover, the results of the measurements can be shared instantly with bartenders, patrons and customers, thus representing an educational opportunity. Real-time monitors can also compare outdoor and indoor air quality instantly, often a shocking experience for lay people who are accustomed to considering pollution mainly as an outdoor problem. ${ }^{21}$ The principal drawback of this marker is its poor specificity to SHS: in order to collect reliable information about exposure, it is sometimes 
useful to link PM measures with other specific markers such as nicotine.*

One commonly used device for measuring SHSderived PM is the TSI SidePak AM510 Personal Aerosol Monitor (TSI, Inc., St. Paul, MN)(Figure 1). The SidePak uses a built-in sampling pump to draw air through the device where the PM in the air scatters the light from a laser. The amount of light scattering is correlated with the particle mass concentration or $\mathrm{PM}_{2.5}$. It is important to note that with any type of light-scattering instrument such as the SidePak, it is important to calibrate the device for the specific aerosol of interest, in this case tobacco smoke. The SidePak has been calibrated and validated for use in studies of SHS exposure. ${ }^{22-26}$ Protocols and a training course to measure SHS exposure using this device are readily available at www.tobaccofreeair.org.

\section{Studies in Latin America}

\section{Air nicotine}

Public places: Between 2002 and 2004, we measured indoor air nicotine concentrations in public places in Argentina, Brazil, Chile, Costa Rica, Guatemala, Honduras, Mexico, Panama, Paraguay, Peru and Uruguay. ${ }^{11,13,27-29}$ In each of the countries, we included two secondary schools, a hospital, a government building, an airport (two airports in Argentina), and 10 restaurants and bars.

Homes: Between 2005 and 2006, we measured indoor air nicotine concentrations in approximately 40 homes of smokers and non-smokers in each of the following countries: Argentina, Brazil, Dominican Republic, Guatemala, Mexico, Panama, Peru, Uruguay, and Venezuela. ${ }^{12}$

Sampling methods: For both studies, the filter-badges were assembled at the Secondhand Smoke Exposure Assessment Laboratory of the Johns Hopkins Institute for Global Tobacco Control and shipped to each country in securely closed smoke-free containers. Trained, incountry investigators placed the small, unnoticeable filter-badges in locations selected to represent areas that people frequently occupy and spend time in. The filterbadges passively filtered the air trapping the nicotine for a period of 7-14 days in each location. At the end of the sampling period, the filter-badges were sent back to the Johns Hopkins laboratory where nicotine was extracted to provide a time weighted average estimate

\footnotetext{
* Agbenyikey W, Wellington E, Gyapong J, Travers M, Breysse PN, McCarty KM, et al. Secondhand tobacco smoke exposure in selected public places (PM2.5 and air nicotine) and non-smoking employees (hair nicotine) in Ghana. Tob Control 2010. In press.
}

of air nicotine concentrations $\left(\mu \mathrm{g} / \mathrm{m}^{3}\right)$ in each location using the method described above. Using this relatively simple method, we have monitored more than 1100 indoor public places (around 100 per country) and 400 homes across major cities in Latin America.

\section{Air nicotine in Latin America - Key findings}

Public places: Airborne nicotine was detected in most locations surveyed $(>90 \%)$ confirming that smoking was widespread in indoor public environments across these Latin American countries between 2002-2004, before the implementation of 100\% smoke-free legislation in Uruguay, Panama, Guatemala and other large cities within Latin America. Nicotine concentrations, however, ranged widely across locations and countries (Figure 2). Concentrations in hospitals, schools and city government buildings were highest in Argentina and Uruguay, followed by Chile and other countries. At the time of the study, legislation banning smoking in schools, hospitals and government buildings were in place in most countries. Our quantification of nicotine, however, revealed incomplete compliance with these laws and the need for better enforcement. The highest nicotine concentrations within all countries were found in bars and restaurants. Air nicotine concentrations were high even in non-smoking areas, showing once more that nonsmoking areas contiguous to smoking areas do not prevent SHS exposure. Most importantly, the high concentrations of SHS measured in restaurants and bars raised major concerns about the health of employees who work long hours in those environments. Our study clearly documented that comprehensive smoke-free laws were urgently needed to protect all people, including workers in the hospitality industry.

Homes: Airborne nicotine was detected in more than $85 \%$ of the homes surveyed. Non-smoking households had very low levels of airborne nicotine although nicotine was detected in nearly $60 \%$ of these homes. The median levels of air nicotine in households with smokers in these Latin American countries ranged from $0.04 \mu \mathrm{g} /$ $\mathrm{m}^{3}$ in Panama, Dominican Republic, and Peru, to 1.19 $\mu \mathrm{g} / \mathrm{m}^{3}$ in Argentina (Figure 3). A major concern was that air nicotine levels in some smoking households were as high as or even higher than air nicotine levels in restaurants or bars in some of the countries. Children, in particular young children, are at high risk of SHS exposure at home since they spend a large amount of time in their homes and because of their limited mobility. ${ }^{30}$

\section{Particulate matter}

In 2006 and $2007 \mathrm{PM}_{2.5}$ was assessed in restaurants, bars, transportation areas such as airports and bus and 

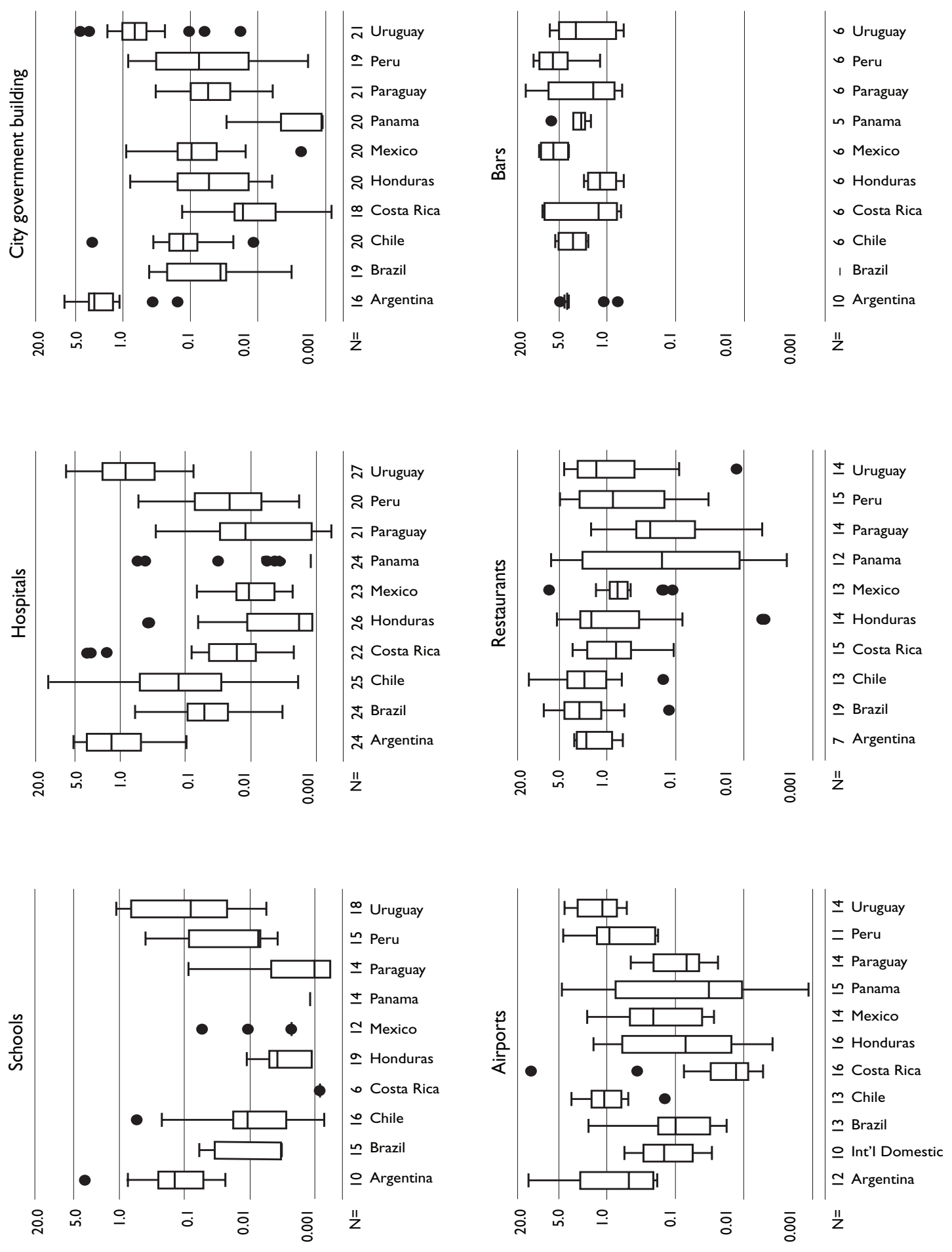


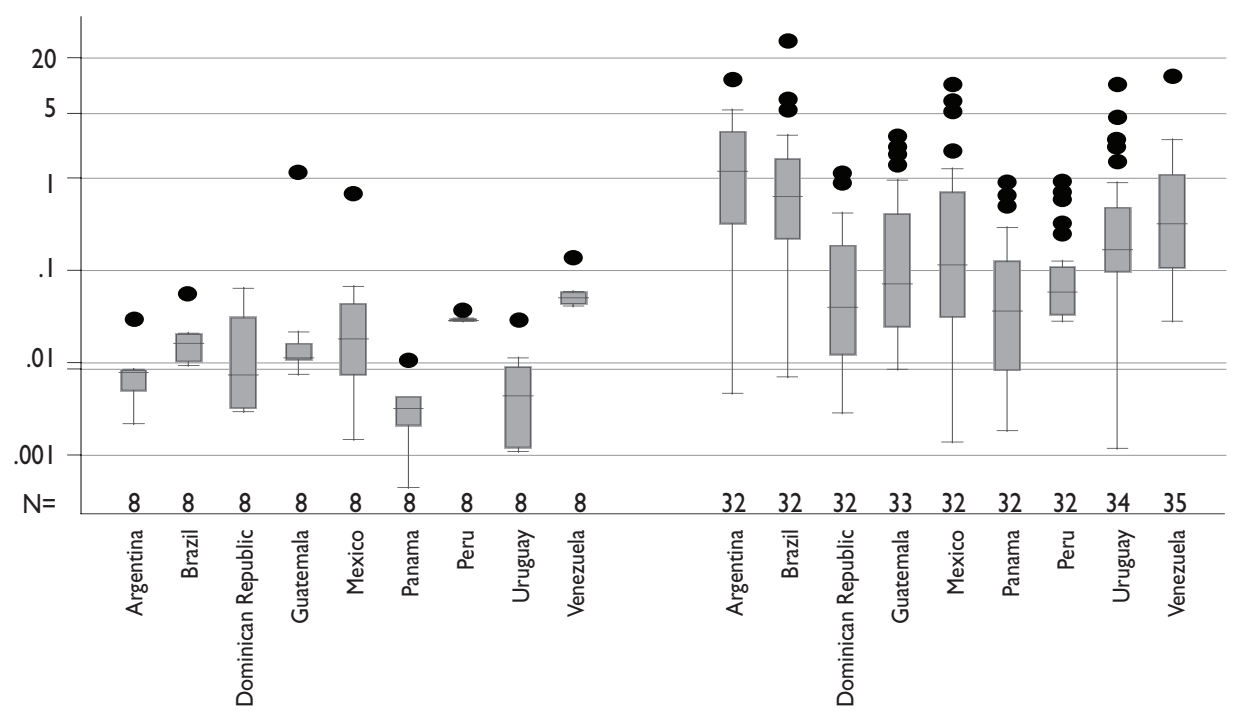

Figure 3.Air nicotine concentrations $\left(\mathrm{g} / \mathrm{M}^{3}\right.$ ) in Homes in Latin America, 2005-2006. Horizontal lines Within boxes INDICATE MEDIANS; BOXES, INTERQUARTILE RANGES; ERROR BARS, VALUES WITHIN I.5 TIMES THE INTERQUARTILE RANGE; SOLID CIRCLES, OUTLYING DATA POINTS

train stations, and other types of venues including hotels, shopping malls, offices, casinos and schools. This study was conducted in 1822 locations in 32 countries around the world ${ }^{31}$ including 385 locations in 5 Latin American countries: Argentina, Brazil, Mexico, Uruguay and Venezuela. In 2008, an additional 79 locations in Panama, and 56 locations in Argentina were added to the previous data collection. All of the sampling in Panama was conducted after Panama implemented nation-wide smoke-free air legislation in April 2008. Each location was visited for a minimum of 30 minutes with the SidePak monitor continuously recording $\mathrm{PM}_{2.5}$ concentrations. The number of people inside the venue and the number of burning cigarettes were recorded every 15 minutes during sampling. These observations were averaged over the time inside the venue to determine the average number of people on the premises and the average number of burning cigarettes. A sonic measuring device was used to measure room dimensions and hence the volume of each of venue where measurements were taken. The active smoker density was calculated by dividing the average number of burning cigarettes by the volume of the room in meters.

\section{Particulate matter - Key findings in Latin America}

Figure 4 shows an overall 5-fold increase in $\mathrm{PM}_{2.5}$ concentration in places where smoking was present at the time of sampling compared to those without smoking. The particle concentrations in the presence of smoking far exceeded limits established by the U.S. Environmental Protection Agency and the World Health Organization to protect human health. Brazil showed a smaller difference between places with and without smoking (2-fold) compared to other Latin American countries. This is due to the higher $\mathrm{PM}_{2.5}$ concentration in the nonsmoking restaurants sampled in Brazil, likely because of the common practice of open-fire cooking in these restaurants. Compliance with the Panama smoke-free air legislation was extremely high with only a single burning cigarette observed indoors in the 79 locations sampled. As a result, public places in Panama had low levels of indoor particulate air pollution. Figure 5 compares 4 locations sampled in smoke-free Colon, Panama to 4 locations sampled in smoking-permitted Olavarria, Argentina. This example plot shows the change in $\mathrm{PM}_{2.5}$ concentrations minute-by-minute as the monitor moved between the outdoors and the four locations in each city. Immediate and dramatic increases in $\mathrm{PM}_{2.5}$ levels are seen in Olavarria as the monitor moves from outdoors to indoor places with smoking. In contrast, in Colon, levels stay low as the monitor moves between the outdoor and indoor smoke-free places.

\section{Using monitoring data in support of smoke-free environments in Latin America}

Dissemination. SHS exposure levels quantified in Latin America between 2002 and 2004 had immediate implications for public health professionals and for the govern- 


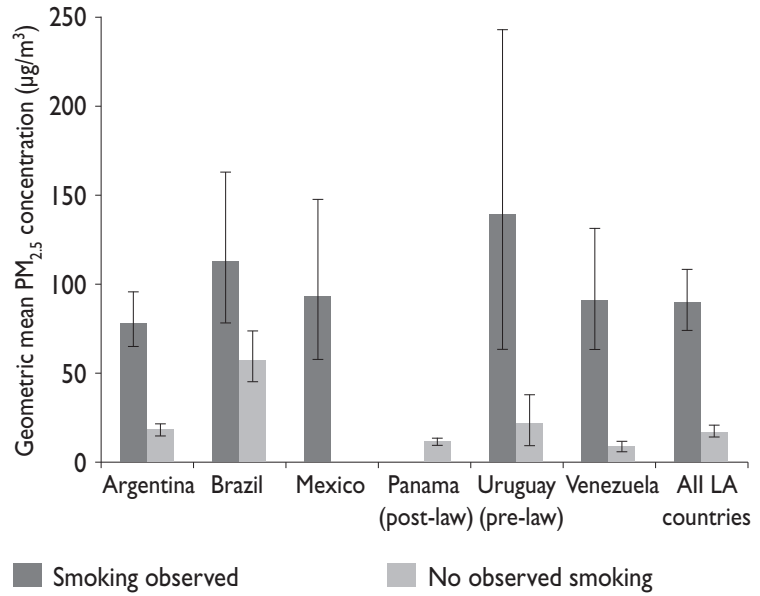

Figure 4. PM $_{2.5}$ Concentrations in public places in Latin America, 2006- 2008. ERror bars RePresent 95\% CONFIDENCE INTERVALS

ment entities responsible for protecting the public from exposure to SHS. The initial peer-review publication of the study of air nicotine levels in public places ${ }^{11}$ received substantial media attention in Latin America. More im- portantly, partner organizations were actively involved in tobacco control activities in their countries. To help them disseminate the study findings, we prepared specific country reports trying to make them attractive and easy to understand. Tips to prepare policy relevant reports are provided in www.shsmonitoring.org. Reports included summary tables, figures, and conclusions highlighting the key points for each country. They also provided details on tobacco legislation at the country level and summarized the international evidence for smoke-free environments. Our target audiences were policy makers, medical and public health providers, media and the public at large.

Some successes. The air nicotine data and the multi-country approach proved to be powerful tools in support of smoke-free environments. Both air nicotine and $\mathrm{PM}_{2.5}$ data have been extensively used for media advocacy in Latin America. The air nicotine findings had a substantial media impact in Latin America, including at least Argentina, Uruguay, Chile and Guatemala and were actively used in support of smoke-free legislations in those countries. $\mathrm{PM}_{2.5}$ results also received very important media coverage in Argentina where $\mathrm{PM}_{2.5}$ monitoring has been used to demonstrate the need for smoke-free air legislation, to evaluate the positive impact of $100 \%$ smoke-free air legislation in some provinces, and to

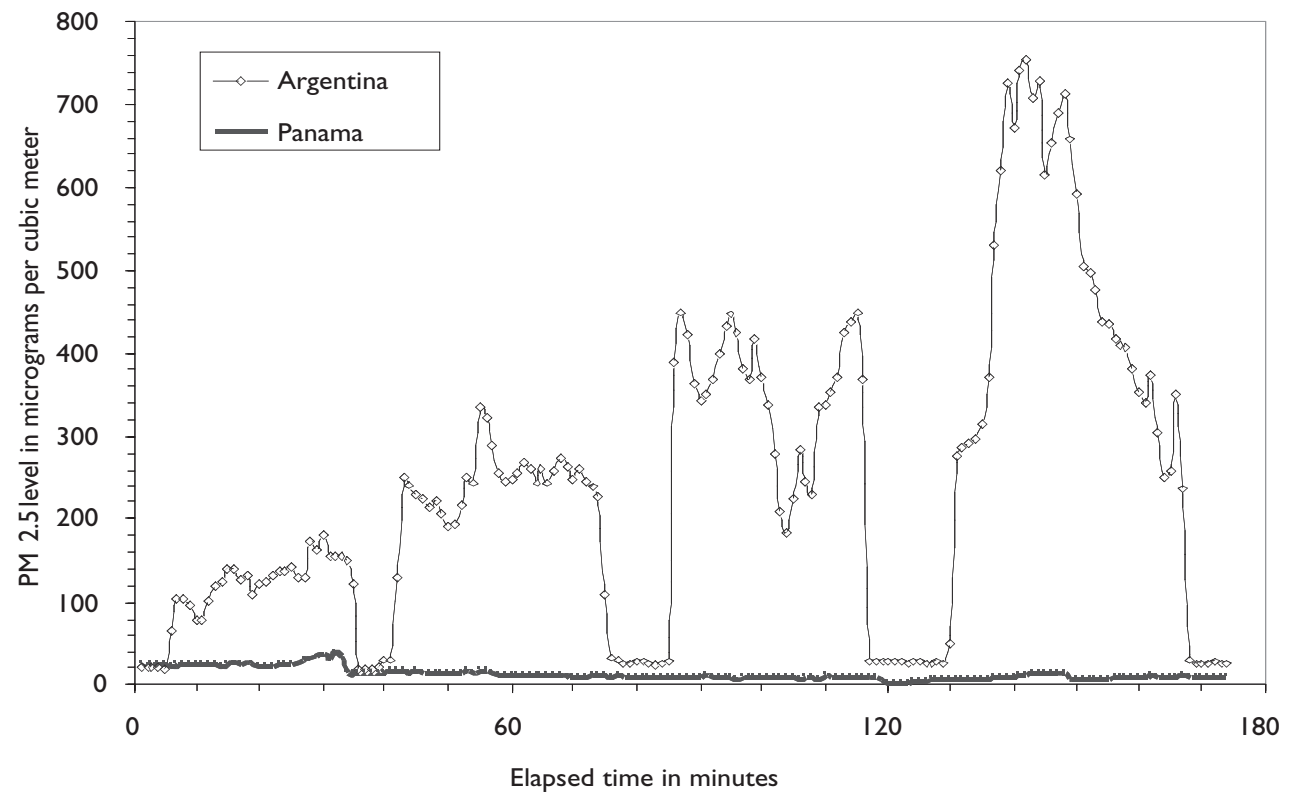

Figure 5. Real-time plot showing PM 2.5 concentrations over time in four locations in Olavarria, Argentina (3 bars and I discotheque), and four locations in Colon, Panama (2 bars and 2 discotheques). All four locations IN OLAVARRIA PERMITTED AND HAD OBSERVED INDOOR SMOKING.ALL FOUR LOCATIONS IN COLON WERE SMOKE-FREE ACCORDING TO NATIONAL LAW AND NO SMOKING WAS OBSERVED 
document the shortcomings of partial restrictions requiring only separate sections. ${ }^{32}$ In most countries, the air nicotine and $\mathrm{PM}_{2.5}$ results were presented to legislative bodies debating tobacco control legislation at the national and sub-national levels. In 2004, the Uruguayan government cited the air nicotine study in a decree that made all health care facilities smoke-free. ${ }^{11}$ Two years later, Uruguay was the first country in the Americas and the first low-or middle-income country in the world to enact comprehensive national smoke-free legislation that prohibited smoking in all indoor public places and workplaces, including bars and restaurants. In 2008, air nicotine data were used in the successful promotion of comprehensive smokefree legislation in Panama and Guatemala and $\mathrm{PM}_{2.5}$ data were used for promotion of sub-national laws in Argentina and in evaluation of the national law in Panama. In other countries, legislation remains incomplete: however, many cities are taking the lead and passing comprehensive smoke-free legislation in their jurisdictions.

\section{Evaluation of smoke-free legislation in Latin America}

We are currently revisiting locations from the 2002-2004 studies in Uruguay ${ }^{33}$ and Guatemala to measure air nicotine concentrations following the implementation of smoke-free legislation in these countries. Our questions are the following: Has exposure to SHS changed? Are levels of enforcement similar across different institutions? Are additional enforcement efforts needed? In Montevideo, Uruguay, air nicotine levels in public places and workplaces have decreased extraordinarily after the implementation of the comprehensive national smokefree legislation in 2006. ${ }^{33}$ These findings, consistent with self-reported data on seeing smoking in regulated venues ${ }^{34}$ confirm that similar legislation can be enacted and implemented successfully in other countries. By objectively documenting decreases in SHS exposure from before to after implementation of comprehensive smokefree legislation, we expect to encourage other countries in Latin America and other regions of the world to take the necessary steps to eliminate toxic tobacco smoke from indoor public places and workplaces.

\section{Next steps}

Measuring air nicotine and respirable suspended particles in public places in Latin America has contributed to increase our understanding of the magnitude of exposure to SHS in Latin America and to use those data to support and promote compliance with smoke-free legislation. The measurement of nicotine in the home environment objectively revealed the critical need to implement educational measures that would protect children from SHS in their homes. Additional efforts to monitor and reduce SHS exposure in private environments, such as homes and motor vehicles, are needed in Latin America. While legislating smoke-free environments in private homes is challenging, ${ }^{35}$ ethical support for banning smoking across different environments can be obtained when the goal is to protect children's health. ${ }^{36}$ These environments could include multi-unit housing, parks and other outdoor places where children gather and spend time, as well as in motor vehicles. There is substantial legislative experience showing that it is possible to ban smoking in cars when children are present. Air nicotine levels ${ }^{37}$ and respirable suspended particles ${ }^{38}$ have been assessed in motor vehicles in some countries and could also be applied in Latin American countries to support smoke-free motor-vehicle legislation there. The source of SHS pollution is easily identifiable: the burning cigarette. Smoke-free environments, through legislation and education, are thus relatively simple and straightforward measures to eliminate tobacco smoke pollution.

\section{Acknowledgements}

Conducting these multi-country studies in Latin America was possible thanks to the collaboration of multiple institutions and investigators. Dr. Armando Peruga from the Pan American Health Organization (PAHO) and Drs. Patrick Breysse, Jonathan Samet and Heather Wipfli from the Johns Hopkins Bloomberg School of Public Health provided the necessary leadership to define the study goals, refine the study methods and protocols and identify the study coordinators and partnering institutions for the air nicotine in public places and home studies. The effective study conduction and dissemination of the findings in each country was possible thanks to the following lead country investigators: Marta Angueira (Argentina), Vera Colombo and Valeska Figueiredo (Brazil), Marisol Acuña (Chile), Katya Jimenez (Costa Rica), Sergio Diaz, Deborah Ossip-Klein and Essie Sierra (Dominican Republic), Joaquin Barnoya (Guatemala), Claudia Gomez (Honduras), Raydel Valdes and Luz Myriam Reynales (Mexico), Reina Roa (Panama), Graciela Gamarra (Paraguay), Carmen Barco (Peru), Adriana Blanco (Uruguay) and Natasha Herrera (Venezuela). The public places nicotine study was originally funded by PAHO and the Institute for Global Tobacco Control, and in recent years by a Clinical Investigator Award from the Flight Attendant Medical Research Institute 
(FAMRI), the FAMRI Center of Excellence Award to the Johns Hopkins Medical Institutions, and the Bloomberg Initiative to Reduce to Tobacco Use. The home nicotine study was funded by FAMRI through a Dr William Cahan Distinguished Professor award to Dr. Jonathan M. Samet. Dr. Travers' work in measuring SHS-derived particulate matter is also funded by FAMRI. The new particle monitoring data presented was made possible by lead investigators Verónica Schoj and María Elizabeth Pizarro in Argentina and Reina Roa in Panama.

\section{Declaration of conflicts of interest}

We declare that we have no conflicts of interest.

\section{References}

I.U.S. Department of Health and Human Services. The Health Consequences of Involuntary Exposure to Tobacco Smoke:A Report of the Surgeon General. Atlanta: U.S. Department of Health and Human Services, Centers for Disease Control and Prevention, Coordinating Center for Health Promotion, National Center for Chronic Disease Prevention and Health Promotion, Office on Smoking and Health, 2006. 2. World Health Organization. WHO Framework Convention on Tobacco Control. Geneva: WHO, 2003.

3. World Health Organization. WHO Framework Convention on Tobacco Control Guidelines for implementation Article 5.3;Article 8;Article II; Article 13. Geneva: WHO, 2009.

4. National Research Council (NRC), Committee on Passive Smoking. Environmental tobacco smoke: Measuring exposures and assessing health effects. Washington, DC: National Academies Press, 1986.

5. Daisey JM. Tracers for assessing exposure to environmental tobacco smoke: what are they tracing? Environ Health Perspect 1999;107(Suppl 2):319-327.

6. Singer BC, Hodgson AT, Guevarra KS, Hawley EL, Nazaroff WW. Gasphase organics in environmental tobacco smoke. I. Effects of smoking rate, ventilation, and furnishing level on emission factors. Environ Sci Technol 2002 Mar I;36(5):846-853.

7. Leaderer BP, Hammond SK. Evaluation of vapor-phase nicotine and respirable suspended particle mass as markers for environmental tobacco smoke. Environ Sci Technol 199| Apr 1;25(4):770-777.

8. Hammond SK, Leaderer BP.A diffusion monitor to measure exposure to passive smoking. Environ Sci Technol 1987;21:494-497.

9. Guerin MR, Jenkins RA, Tomkins BA. The chemistry of environmental tobacco smoke: composition and measurement. 2nd. ed.Washington, DC: Lewis Publishers Inc., 1992.

10. Hammond SK, Leaderer BP, Roche AC, Schenker M. Collection and analysis of nicotine as a marker for environmental tobacco smoke. Atmospheric Environment 1987;21(2):457-462.

I I. Navas-Acien A, Peruga A, Breysse P, Zavaleta A, Blanco-Marquizo A, Pitarque $R$, et al. Secondhand smoke in public places in Latin America, 2002-2003. JAMA 2004:29I(22):274I-2745.

12. Wipfli H,Avila-Tang E, Navas-Acien A, Kim S, Onicescu G, Yuan J, et al. Secondhand smoke exposure among women and children: Evidence from 3 I countries. Am J Public Health 2008;98(4):672-679.

13. Barnoya J, Mendoza-Montano C, Navas-Acien A. Secondhand smoke exposure in public places in Guatemala: comparison with other Latin American countries. Cancer Epidemiol Biomarkers Prev 2007;16(I2):2730-2735.
14. Environmental Protection Agency. PM Standards Revision - 2006. http://www epa gov/oar/particlepollution/naaqsrev2006 html 2007 [cited 2010 Mar II];Available from:URL: http://www.epa.gov/oar/ particlepollution/naaqsrev2006.html

15. World Health Organization. WHO Air quality guidelines for particulate matter, ozone, nitrogen dioxide and sulfur dioxide. Global update 2005. Summary of risk assessment. Geneva: WHO, 2006.

16. Klepeis NE,Apte MG, Gundel LA, Sextro RG, NazaroffWW. Determining size-specific emission factors for environmental tobacco smoke particles.Aerosol Science and Technology 2003;37(10):780-790. 17. Morawska L, Barron W, Hitchins J. Experimental deposition of environmental tobacco smoke submicrometer particulate matter in the human respiratory tract. American Industrial Hygiene Association Journal 1999;60(3):334-339.

18. Ott WR, Siegmann HC. Using multiple continuous fine particle monitors to characterize tobacco, incense, candle, cooking, wood burning, and vehicular sources in indoor, outdoor, and in-transit settings. Atmospheric Environment 2006;40:821-843.

19. National Cancer Institute. Smoking and Tobacco Control Monograph 10. Health Effects of Exposure to Environmental Tobacco Smoke, Final Report. 1999.

20. Repace J. Respirable particles and carcinogens in the air of delaware hospitality venues before and after a smoking ban.J Occup Environ Med 2004;46(9):887-905.

21. Invernizzi G, Ruprecht A, Mazza R, Rossetti E, Sasco A, Nardini S, et al. Particulate matter from tobacco versus diesel car exhaust: an educational perspective. Tobacco Control 2004;13(3):219-221.

22. Klepeis NE, OttWR, Switzer P. Real-time measurement of outdoor tobacco smoke particles 6. Journal of the Air \& Waste Management Association 2007;57(5):522-534.

23. Travers MJ, Cummings KM, Hyland A, Repace J, Babb S, Pechacek T, et al. Indoor air quality in hospitality venues before and after implementation of a clean indoor air law --Western New York, 2003. MMWR: Morbidity \& Mortality Weekly Report 2004;53(44): 1038-104I.

24. Travers MJ, Lee K. Particulate air pollution in Irish pubs is grossly underestimated. Am J Respir Crit Care Med 2008;177(2):236-237.

25. Waring MS, Siegel JA.An evaluation of the indoor air quality in bars before and after a smoking ban in Austin, Texas.J Expo Sci Environ Epidemiol 2007;17(3):260-268.

26. Lee K, Hahn EJ, Pieper N, Okoli CT, Repace J,Troutman A. Differential impacts of smoke-free laws on indoor air quality.J Environ Health 2008;70(8):24-30, 54

27. Navas-Acien A, Blanco-Marquizo A, Goja B. Estudio de vigilancia de la exposición a humo de tabaco en Uruguay. Rev Salud Publica de Uruguay 2004:2:3-8.

28. Navas-Acien A, Gómez Mass CDHACE. Exposición ambiental a humo de tabaco en Tegucigalpa, Honduras. Revista Facultad Ciencias Médicas Hondureña 2005;2:5I-59.

29. Barrientos-Gutierrez T,Valdes-Salgado R, Reynales-Shigematsu LM, Navas-Acien A, Lazcano-Ponce E. [Involuntary exposure to tobacco smoke in public places in Mexico City]. Salud Publica Mex 2007;49 Suppl 2:S205-S2I2.

30. Kim S,Wipfli H, Navas-Acien A, Dominici F, vila-Tang E, Onicescu G, et al. Determinants of hair nicotine concentrations in nonsmoking women and children: a multicountry study of secondhand smoke exposure in homes. Cancer Epidemiol Biomarkers Prev 2009;18(I2):3407-34I4. 31. Hyland A, Travers MJ, Dresler C, Higbee C, Cummings KM.A 32-country comparison of tobacco smoke derived particle levels in indoor public places. Tob Control 2008;17(3):159-165. 32. Schoj V, Sebrie E, Pizarro M, Hyland A, Travers MJ. Informing effective smokefree policies in Argentina: air quality monitoring study in 15 cities (2007-20009). Salud Publica Mex 2010. 
33. Blanco-Marquizo A, Goja B, Peruga A, Jones MR, Yuan J, Samet JM, et al. Reduction of secondhand tobacco smoke in public places following national smoke-free legislation in Uruguay. Tobacco Control. 2010;19:231-234.

34. Thrasher JF, Boado M, Sebrie EM, Bianco E. Smoke-free policies and the social acceptability of smoking in Uruguay and Mexico: Findings from the International Tobacco Control Policy Evaluation Project. Nicotine \& Tobacco Research 2009; I I (6):591-599.

35. Jarvie JA, Malone RE. Children's secondhand smoke exposure in private homes and cars: an ethical analysis. Am J Public Health 2008;98(I2):2140-2|45.
36. Tobacco and the Rights of the Child. World Health Organization Tobacco and the Rights of the Child Web site. [accessed December, 2009]. Available at: http://www.who.int/tobacco/media/en/CRCreport.pdf 37. Jones MR, Navas-Acien A, Yuan J, Breysse PN. Secondhand tobacco smoke concentrations in motor vehicles: a pilot study. Tob Control 2009; |8(5):399-404.

38. Sendzik T, Fong GT, Travers MJ, Hyland A.An experimental investigation of tobacco smoke pollution in cars. Nicotine Tob Res 2009; I (6):627-634. 